\title{
Surgical and Anesthesiological Considerations of Awake Craniotomy: Cerrahpasa Experience
}

\author{
Uyanı Kraniyotominin Cerrabi ve Anestezi Hususlar: \\ Cerrabpaşa Deneyimi
}

Galip Zihni SANUS ${ }^{1}$, Odhan YUKSEL ${ }^{1}$, Yusuf TUNALI ${ }^{2}$, Cigdem OZKARA ${ }^{3}$, Naz YENI ${ }^{3}$, Fatma OZLEN ${ }^{1}$, Taner TANRIVERDI ${ }^{1}$, Emin OZYURT ${ }^{1}$, Mustafa UZAN ${ }^{1}$

${ }_{1}^{1}$ Istanbul University, Cerrahpasa Medical Faculty, Department of Neurosurgery, Istanbul, Turkey

2Istanbul University, Cerrahpasa Medical Faculty, Department of Anesthesiology, Section of Neuroanesthesiology, Istanbul, Turkey

${ }^{3}$ Istanbul University, Cerrahpasa Medical Faculty, Department of Neurology, Istanbul, Turkey

Corresponding Author: Yusuf TUNALI / E-mail: ytunali@yahoo.com

\begin{abstract}
AIM: Awake craniotomy (AC) with electrical cortical stimulation has become popular during the last ten years although the basic principles were introduced almost 50 years ago. The aim of this paper is to share with the readers our experience in 25 patients who underwent AC with electrical stimulation.

MATERIAL and METHODS: Twenty-five patients who underwent AC between 2010 and 2013 are the subjects of this paper. All patients were diagnosed with intraaxial lesions involving the functional area itself or very close to it by preoperative imaging. During surgery, the functional area was demonstrated by cortical electrical stimulation and resection aimed to preserve it in order to avoid an irreversible functional deficit.

RESULTS: Total resection was possible in $80 \%$ while in $20 \%$ subtotal resection had to be performed because of involvement of the functional area itself. The neurological complication rate was found to be $16 \%$ (4 patients) and all were transient. No complication regarding anesthesia was noted.
\end{abstract}

CONCLUSION: Awake craniotomy in selected patients is very effective, safe and practical for supratentorial lesions close to the eloquent area. Complications related to the surgery itself are uncommon and general anesthesia is avoided. The hospital stay including the intensive care unit is short which makes it very economical surgical procedure.

KEYWORDS: Awake craniotomy, Brain tumors, Cerebral cortex, Electrical stimulation, Epilepsy

öz

AMAÇ: Temel prensipleri 50 yıl önce ortaya konmasına rağmen, elektrik kortikal uyarım ile yapılan uyanık kraniyotomi (UK) son on yıldır popüler olmuştur. Çalışmanın amacı elektrik uyarım ile birlikte 25 hastada yapılan UK tecrübemizi okuyucu ile paylaşmaktır.

YÖNTEM ve GEREÇLER: Makalenin konusu 2010 ile 2013 yılları arasında UK yapılan 25 hastadır. Ameliyat öncesi alınan görüntülemelerle tüm hastalarda fonksiyonel bölgeyi tutan veya o bölgelere çok yakın intraaksiyel lezyon tanısı kondu. Cerrahi sırasında fonksiyonel alanlar elektrik uyarım ile belirlendi ve geriye dönüşü olmayan nörolojik defisitlerden kaçınmak için o bölgeler korundu.

BULGULAR: Total rezeksiyon \% 80'inde ve fonksiyonel alanın kendisinin tutulumu nedeni ile subtotal rezeksiyon \% 20 'sinde yapıldı. Nörolojik komplikasyon oranı \% 16 (4 hasta) olarak bulundu ve hepsi geçici idi. Anesteziye bağlı komplikasyon görülmedi.

SONUÇ: Seçilmiş hastalarda ve bölgelere yakın supratentoriyel lezyonlarda uyanık kraniyotomi etkili, güvenli ve pratiktir. Cerrahiye bağlı komplikasyon oranı düşüktür ve genel anesteziye bağlı komplikasyonlar ortadan kalkmaktadır. Yoğun bakım dahil hastanede kalıs süresinin kısa olması nedeniyle uyanık kraniyotomi ekonomik olmaktadır.

ANAHTAR SÖZCÜKLER: Beyin tümörleri, Elektrik uyarım, Epilepsi, Serebral korteks, Uyanık kraniyotomi

\section{INTRODUCTION}

It is clear that awake craniotomy (AC) arose from its use in epilepsy surgery and it has become an increasingly frequent neurosurgical procedure, even for supratentorial tumoral and/ or non-tumoral lesions (16). This method is generally used when a lesion involves or is close to any functional or eloquent area, such as primary motor or language cortices, in order to reduce the possibility of neurological deficits. However, there has been some criticism that AC for preservation of functional areas may decrease the extent of surgical resection (7). Evidence against such criticism could only come from prospective clinical studies comparing awake and traditional procedures. Unfortunately there have only been a limited number of clinical prospective studies in the literature but the results demonstrated that awake surgery may also result in extensive resection in low-grade gliomas involving the functional areas and significantly improve quality of life of patients (13-16). Evolutionary stages with respect to 
this neurosurgical intervention involve the development of surgical techniques, use of new anesthetic drugs and advanced preoperative functional imaging, tractography and neuronavigation. However, we have to emphasize that the success of AC depends on experienced surgical and anesthesia teams in order to keep the patients awake for direct cortical electrical stimulation and neurological examination during surgery.

The authors in the present paper demonstrated surgical and anesthesiological considerations and experience with the results of a series of patients who underwent $A C$ due to supratentorial lesions involving or close to the functional areas..

\section{MATERIAL and METHODS}

\section{Patient Population}

In this series, all patients operated on were diagnosed with intra-axial lesions including tumors, cortical dysplasias or non-lesional epilepsy with preoperative imaging studies and direct electrical cortical stimulations were performed during surgery. Patients were evaluated and discussed in the preoperative meetings held routinely once a week in the department and informed consent from each patient or their closest relative was obtained before surgery. The meticulous criteria for undergoing $A C$ were the age that should be at least 16 years and patient's ability to cooperate. Each patient was seen a day before surgery and specifically evaluated for eligibility for AC by the same anesthetist. The respiratory system was specifically considered as it could increase intracranial pressure during surgery if there was a problem. In case of anxiety, the anesthesiology team prescribed an oral benzodiazepine derivative for the evening before surgery. All operations were performed or supervised by the same surgical and anesthesia teams.

\section{Monitorization and Anesthesia}

On the day of surgery, premedication with intravenous midazolam (30-50 $\mu \mathrm{g} / \mathrm{kg}$ ) was given in order to prevent anxiety, nausea/vomiting and seizure. Next step was the non-invasive monitorization including electrocardiography, arterial pressure, and temperature. It is especially suggested that the state of alertness should be considered objectively for such operations and the bispectral index (BIS) monitor has entered operating rooms for the purpose of objective monitoring of alertness (4). At the beginning of craniotomy, the BIS value should be between 60 and 80 but when neurological examination is needed the target value has to be greater than 80 . A nasopharyngeal airway is required both for giving oxygen and monitoring the end tidal $\mathrm{CO}_{2}$ and an invasive arterial catheter should be inserted under local anesthesia in order to take samples or arterial blood gas analysis and frequent monitoring of the real arterial blood pressure. An indwelling urinary catheter is especially useful in case diuretics are given for decreasing unwanted increased intracranial pressure during surgery. It is clear that patient's respiratory sounds and skin color should be monitored.
Our technique used in AC is "asleep-awake-asleep" as described in the literature (8). Neurolept anesthesia was used in the past but subsequently this technique was abandoned mainly because of unwanted deep sedation, pain and a high seizure incidence. Currently, short-acting anesthetic agents such as dexmedetomidine (0.02-0.5 $\mu \mathrm{g} / \mathrm{kg} / \mathrm{hour})$, propofol (30-180 $\mu \mathrm{g} / \mathrm{kg} / \mathrm{hour}$ ), and remifentanil (0.03-0.09 $\mu \mathrm{g} / \mathrm{kg} /$ hour) are used. In addition to intravenous anesthetic agents, local anesthetics are also required for skin incision and local peripheral nerves such as the supraorbital nerve. The anesthesiology team should be ready in case of failure of AC and unexpected situations such as seizure, airway problems, increased intracranial pressure and severe drug allergy.

\section{Surgery}

After the anesthesia team is completed their routine, the surgical team took care of the patient. All patients were given antibiotics, anti-convulsants and corticosteroids immediately before surgery. One of the most important issues that the surgical team is that the patient should be in a comfortable position and that there should be no stress for the head. The head position is generally neutral for venous return which should not be obstructed. The head is fixed with either the Mizuho or Mayfield head holder. Pin sites routinely are administered local anesthesia. After fixation, the skin incision is planned, which should lead the surgeon to the target by the shortest distance. The skin incision should be minimumaccess incision. The incision site is administered local anesthesia before draping the operative field. In general, our team performs local anesthesia to the skin incision site only without peripheral nerve (eg., supraorbital nerve, occipital nerve etc.) local anesthesia. The incision site is generally infiltrated with $0.25 \%$ marcaine. Dural opening generally does not cause discomfort and when pain is felt by the patient we infiltrate the dura with small amounts of local anesthetic agent.

\section{Electrical Mapping}

After opening the dura and exposing the pia, the lesion is verified by observation and neuronavigation if available. A bipolar stimulator with a ball tip is brought to the operating table. The device is set to $50-\mathrm{Hz}$ repetition and $100 \mu \mathrm{sec}$ square wave pulse. The intensity of stimulation is begun at 1 $\mathrm{mA}$ and increased up to $15 \mathrm{~mA}$ with $1 \mathrm{~mA}$ increments. During stimulation, the anesthesiologist or a senior resident observes the movements of face, arm or leg. Each site is tested three times to be sure that the area of interest is accurate. Cortical areas essential for language are tested by asking the patient to name the list of the objects (animals etc.) and speech arrest, dysnomia or hesitation is observed. When functional areas are identified, a small piece of paper is placed to that area. Following the identification of the functional areas, cortical or lesion resection is performed. We generally perform subcortical electrical stimulation as well for identification of the functional or eloquent white matter. In every case, we try to perform gross-total removal or excision and to spare the functional areas. 


\section{Postoperative Care}

Depending on the patient's general and neurological condition, the anesthesia team decides on whether the patient would go to the intensive care unit (ICU) or the ward.

\section{RESULTS}

\section{Patient Demographics}

The patient group presented here underwent $A C$ by the same surgical and anesthetic team between July 2010 and February 2013 at Cerrahpasa Epilepsy Center. The group consisted of 17 males and 8 females with a mean age of 34.25 years. Table I provides a summary of demographic data of the group. All craniotomies were the first procedure and no biopsy was performed. The most common presenting symptom was seizure, followed by weakness and headache. There was no patient with any comorbidity that could affect the clinical condition before surgery. In the preoperative period, magnetic resonance imaging (MRI) of the head was performed in all patients and in patients in whom cortical dysplasia was suspected on 1.5 T MRI, 3T MRI was considered. Tractography and functional MRI were done in 11 and 14 patients, respectively.

\section{Radiological and Lesion Features}

Table II shows the radiological and lesion characteristics. Fourteen patients had left and 11 right hemispheric lesions. The majority of the lesions were located on the frontal lobe, followed by insular and/or temporal lobes. The absence of occipital lesion in the present paper is due to our exclusion of patients with occipital lesion that makes AC difficult because of positioning problems. The histopathological diagnosis was glioma in $56 \%$, cavernous malformation in $20 \%$, focal cortical dysplasia in $16 \%$, and the remaining 2 patients were diagnosed as malignant germ cell metastasis and dysembryonic neuroepithelial tumor (DNET), respectively.

\section{Surgical Findings}

There was no unsuccessful brain mapping and estimated functional areas were identified by stimulation in all cases. Positive and negative mappings guided us for safe resection and in cases in which mapping was positive subtotal resection or gross total resection was performed (Figure $1 A, B ; 2 A-D$ ). There was no case in which $A C$ failed. Following identification of the functional area, resection was started furthest from the functional area and neurological examination was performed every minute. Meticulous attention was paid to respect the uninvolved cortex by applying subpial resection. No intraoperative seizure was noted. Range of operation time from the skin incision to closure was 2 to 5 hours and glioma surgery took generally time compared to cavernous hemangiomas or focal cortical dysplasia.

\section{Postoperative Care and Complications}

Only four patients (16\%) stayed in the ICU postoperatively and all four had insular involvement. The range of ICU stay was 1 to 2 days and as the team experience increased the median length of ICU stay showed a trend to become shorter at 1 day. The median length of postoperative hospital stay was found to be 5 days. In every patient, postoperative MRI was obtained within 24 hours in order to have an idea about the resection rate regarding tumors that was evaluated according to Berger et al. (1). In case of cortical dysplasia and cavernoma, FLAIR and $\mathrm{T}_{2}$-weighted MRI images were evaluated for deciding whether total removal has been performed. Table III shows summary of clinical data including the follow-up period. Total resection was identified in 20 cases ( $80 \%$ ) and subtotal resection had to be performed in 5 ( $20 \%$ ) because of involvement of the functional area itself.

There was no mortality in this series and overall complication rate was 16\% (4 patients) and all were transient. One patient

Table I: Summary of Demographic Data of the 25 Patients Underwent Awake Craniotomy

\begin{tabular}{|c|c|c|c|c|}
\hline No & Age & Gender & Seizure & $\begin{array}{l}\text { Neurological } \\
\text { examination on } \\
\text { admission }\end{array}$ \\
\hline 1 & 19 & $M$ & Yes & Normal \\
\hline 2 & 43 & $M$ & Yes & Dysarthria \\
\hline 3 & 35 & $\mathrm{~F}$ & Yes & Normal \\
\hline 4 & 30 & M & No & Apraxia on the left hand \\
\hline 5 & 28 & M & Yes & Apraxia on the left hand \\
\hline 6 & 20 & M & No & Left hemiparesis \\
\hline 7 & 68 & M & No & Left hemiparesis \\
\hline 8 & 36 & M & No & $\begin{array}{l}\text { Dysarthria }+ \\
\text { Hypoesthesia on the } \\
\text { left upper extremity }\end{array}$ \\
\hline 9 & 20 & $\mathrm{~F}$ & Yes & Normal \\
\hline 10 & 55 & M & Yes & $\begin{array}{l}\text { Weakness on the left } \\
\text { hand extension }\end{array}$ \\
\hline 11 & 39 & $M$ & No & Apraxia on the left hand \\
\hline 12 & 19 & M & Yes & Normal \\
\hline 13 & 55 & M & No & $\begin{array}{l}\text { Weakness on the left } \\
\text { hand extension }\end{array}$ \\
\hline 14 & 25 & $M$ & Yes & Normal \\
\hline 15 & 54 & M & No & Left hemiparesis \\
\hline 16 & 57 & $\mathrm{~F}$ & No & Normal \\
\hline 17 & 22 & $\mathrm{~F}$ & Yes & Normal \\
\hline 18 & 27 & $M$ & No & Normal \\
\hline 19 & 27 & $\mathrm{~F}$ & Yes & Normal \\
\hline 20 & 22 & $M$ & Yes & Normal \\
\hline 21 & 22 & $M$ & Yes & Normal \\
\hline 22 & 44 & $\mathrm{~F}$ & No & Normal \\
\hline 23 & 32 & $M$ & Yes & Normal \\
\hline 24 & 27 & $\mathrm{~F}$ & Yes & Normal \\
\hline 25 & 42 & M & Yes & Normal \\
\hline
\end{tabular}



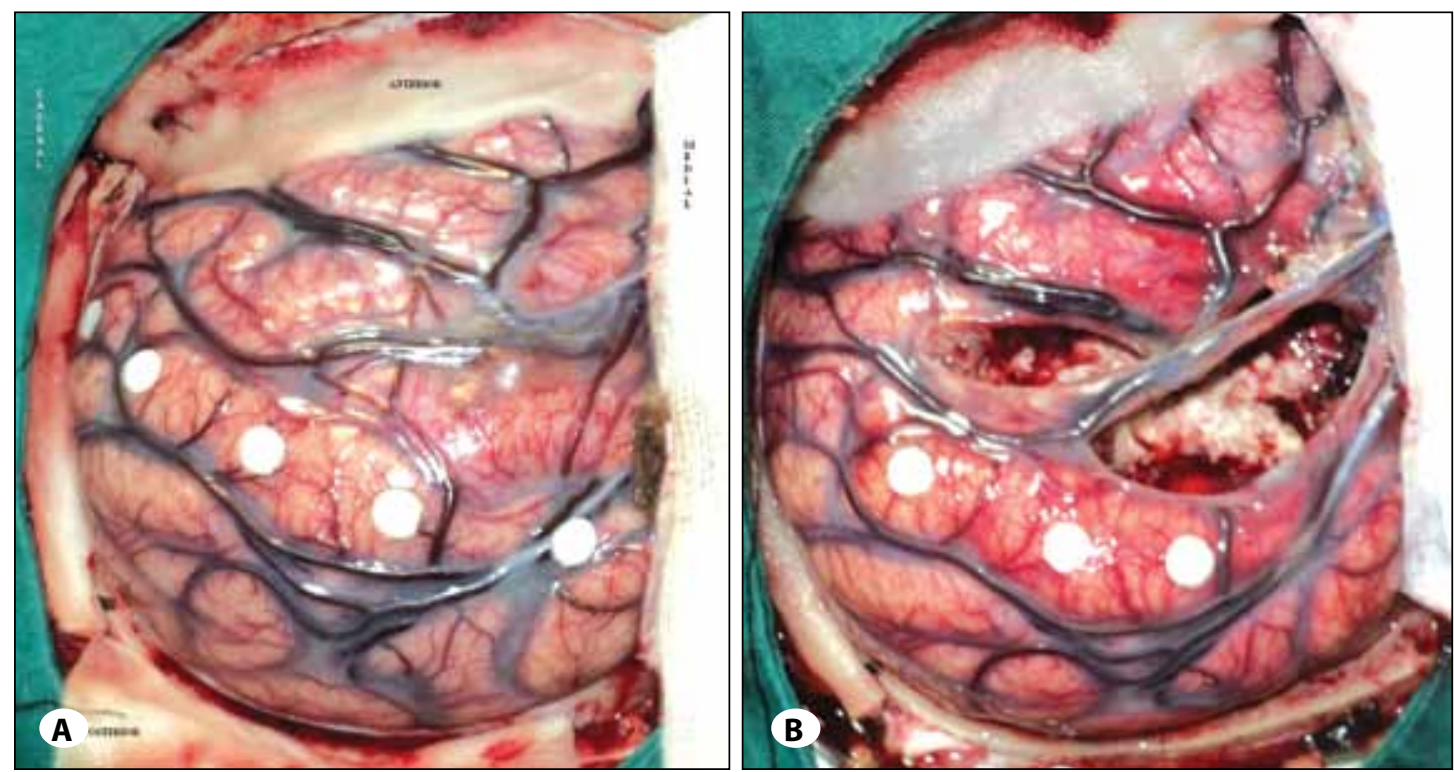

Figure 1: This 22-year-old female was admitted to our clinic with intractable seizure. Preoperative work-up disclosed focal cortical dysplasia just anterior to the left precentral gyrus. She underwent awake craniotomy and electrical cortical stimulation was performed before surgery in order to locate the precentral gyrus (A). Depicted area with small spherical piece of paper shows the precentral gyrus. Note that without stimulation it would be difficult to locate the precentral gyrus depending only on the knowledge of gross anatomy. Resection was performed safely just anterior to the left precentral gyrus in this patient (B) and no neurological deficit was detected. The patient was free of seizures during the long-term follow-up.
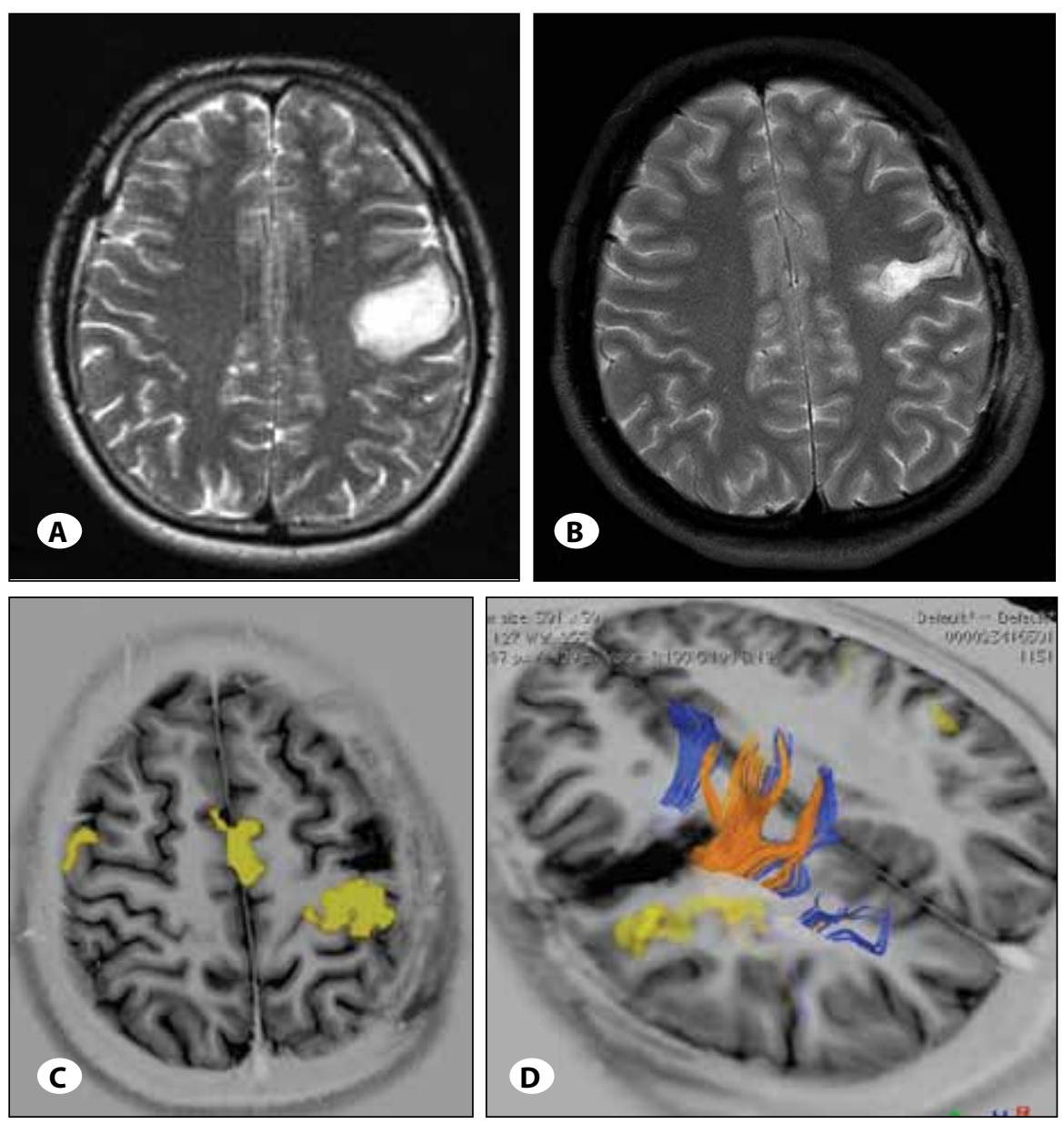

Figure 2: This 27-year-old male patient who was complaining of seizures underwent awake craniotomy because of a tumor located just anterior to the left middle and lower motor strip (A). With the help of electrical stimulation, the tumor was removed totally (B) without any motor deficit that was also demonstrated by postoperative functional magnetic resonance imaging (C). Tractography shows the preservation of the motor fibers just posterior to the motor strip beautifully (D). 
with GBM located in the left premotor and extending to the supplementary motor (SMA) area showed SMA syndrome that was characterized by aphasia and right hemiparesis that resolved within 15 days. There were two patients who had weakness in the left upper extremities due to resection of low-grade glioma involving the right premotor area and that resolved within one month of the surgery. One patient showed right hemiparesis predominantly involving the right upper extremity. The lesion involved the left premotor and precentral gyri complex, which was removed subtotally due to the motor strip involvement. In the third month follow-up the patient was found to be neurologically intact. There were four patients with GBM. All had received both radiotherapy and chemotherapy and are still under our follow-up (almost 1 year without recurrence).

\section{DISCUSSION}

"As a neurosurgeon, it has been my lot to watch the experiments which only disease and injury can carry out upon the brains of unfortunate men and women. Of recent years my special province has been the surgical treatment of epilepsy, removing abnormal areas of the brain, areas in which the unbridled electrical discharges arise that produce epileptic seizures. There are many brain areas that can be removed with little or no detectable functional loss. During such surgical procedures, the skull is opened and the brain exposed under local anesthesia, while the patient lies on the operating table fully conscious. Only thus is the cause of the attack to be found, and the surgeon's hand guided. The patient talks and answers the surgeon's questions while he maps out the various functional areas by applying a gentle electrical stimulus here and there on the cortex". The above statement is from Wilder Penfield who with Andre Pasquet initiated the modern era of $A C$ when they published

Table II: Summary of Radiological and Histopathological Features of the Lesions

\begin{tabular}{|c|c|c|c|c|}
\hline No & Side & Site & $\begin{array}{l}\text { Resection rate } \\
(\%)\end{array}$ & Histopathological diagnosis \\
\hline 1 & Left & Postcentral gyrus and posterior to it & 100 & $\begin{array}{l}\text { Dysembryoplastic neuroepithelial } \\
\text { tumor }\end{array}$ \\
\hline 2 & Left & Anterior to precentral gyrus & 100 & Cavernoma \\
\hline 3 & Right & Anterior to precentral gyrus & 100 & Oligodendroglioma \\
\hline 4 & Left & Anterior to supplementary motor area & 100 & Cavernoma \\
\hline 5 & Right & Anterior to precentral gyrus & 100 & Focal cortical dysplasia \\
\hline 6 & Right & Precentral gyrus and anterior to it and thalamus & 50 & Oligodendroglioma \\
\hline 7 & Right & Premotor area & 100 & Astrocytoma \\
\hline 8 & Left & $\begin{array}{l}\text { Anterior to precentral gyrus including } \\
\text { supplementary motor area }\end{array}$ & 100 & Glioblastoma multiforme \\
\hline 9 & Right & Temporal lobe and insula & 80 & Oligodendroglioma \\
\hline 10 & Right & Central area and anterior to it & 80 & Glioblastoma multiforme \\
\hline 11 & Right & Premotor and supplementary motor area and insula & 90 & Oligodendroglioma \\
\hline 12 & Right & Anterior to precentral gyrus & 100 & Metastasis \\
\hline 13 & Right & Precentral gyrus and anterior to it & 80 & Glioblastoma multiforme \\
\hline 14 & Left & Anterior to precentral gyrus & 100 & Oligodendroglioma \\
\hline 15 & Right & Anterior to precentral gyrus & 100 & Glioblastoma multiforme \\
\hline 16 & Left & Anterior to precentral gyrus & 100 & Astrocytoma \\
\hline 17 & Left & Anterior to precentral gyrus & 100 & Focal cortical dysplasia \\
\hline 18 & Left & Anterior to Broca & 100 & Cavernoma \\
\hline 19 & Left & $\begin{array}{l}\text { Between supplementary motor area and cingulate } \\
\text { gyrus }\end{array}$ & 100 & Focal cortical dysplasia \\
\hline 20 & Left & Between Wernicke and Heschl gyrus & 100 & Focal cortical dysplasia \\
\hline 21 & Left & Anterior to Broca & 100 & Cavernoma \\
\hline 22 & Left & Precentral gyrus & 100 & Cavernoma \\
\hline 23 & Left & Lower postcentral gyrus and insula & 100 & Glioma grade II \\
\hline 24 & Left & Precentral gyrus and anterior to it and insula & 90 & Glioma grade II \\
\hline 25 & Right & Central sulcus & 100 & Cavernoma \\
\hline
\end{tabular}


Table III: Summary of Clinical Data After Surgery

\begin{tabular}{|c|c|c|c|}
\hline No & Intensive care unit stay (day) & Last follow-up & Neurological examination at the last follow-up \\
\hline 1 & None & 55 month & None \\
\hline 2 & None & 55 month & None \\
\hline 3 & None & 22 month & Weakness on the left hand \\
\hline 4 & None & 24 month & None \\
\hline 5 & None & 14 month & None \\
\hline 6 & None & 14 month & Hemiparesis predominate on the right upper extremity \\
\hline 7 & None & 14 month & None \\
\hline 8 & None & 12 month & Supplementary motor area syndrome \\
\hline 9 & 1 & 12 month & None \\
\hline 10 & None & 12 month & None \\
\hline 11 & 2 & 12 month & None \\
\hline 12 & None & 12 month & Weakness on the left hand \\
\hline 13 & None & 12 month & None \\
\hline 14 & None & 8 month & None \\
\hline 15 & None & 8 month & None \\
\hline 16 & None & 8 month & None \\
\hline 17 & None & 3 month & None \\
\hline 18 & None & 3 month & None \\
\hline 19 & None & 2 month & None \\
\hline 20 & None & 2 month & None \\
\hline 21 & None & 1 month & None \\
\hline 22 & None & 1 month & None \\
\hline 23 & 1 & 25 days & None \\
\hline 24 & 2 & 20 days & None \\
\hline 25 & None & 15 days & None \\
\hline
\end{tabular}

their landmark paper with respect to surgical and anesthetic aspects of these surgical procedures $(11,12)$. Now we see clearly that the concepts that they underlined years ago are still relevant and are being applied in many neurosurgical centers in the world today. However, Dr. Harvey Cushing was the first to perform local anesthesia or AC to operate on a series of patients and describe the sensory cortex in man (3). He published two patients with epilepsy, who underwent anesthesia with chloroform and morphine and were allowed to awaken after the craniotomy. Cushing used faradic stimulation in both patients and observed sensory responses from the area just posterior to the central sulcus. Later on, Otfried Foerster in Breslau performed surgery with local anesthesia and extensive sensorimotor cortical stimulation to find the epileptic focus by reproducing habitual seizures (5). Foerster's extensive use of AC was inspired by Penfield during his stay with him and brought this procedure to Montreal in 1928 and the modern era of this surgical procedure began there as outlined above. Although use of new technology such as neuronavigation has decreased the use of AC (10), it still continues to be an important surgical technique that should be used in specific conditions.
Functional cerebral localization with direct cortical electrical stimulation is still considered to be gold standard and the only direct way to localize the functional eloquent areas. It guides the surgeon to perform as much resection as possible without unacceptable functional deficits that could affect the quality life of patient. Recent years have shown us us that $A C$ is performed by many centers not only for lesions involving the eloquent cortex but also any supratentorial intra-axial lesions regardless of the involvement of the functional areas (13-16). Shifting of the general anesthesia to local in neurosurgical arena is mainly due to the fact that $A C$ is a safe and practical method and more importantly is economic with a low complication rate, which means patients are discharged from the hospital in a short time. Recent reports demonstrated that this method of surgery is not contraindicated in increased intracranial pressure as well (2). A limited number of prospective studies reported in the English literature have suggested that the use of ACs provides maximum resection with minor or without neurological deficit and is safe technique that is an excellent alternative to craniotomy under general anesthesia (7, 13-16). Furthermore, they concluded that this method results in substantial reduction in resource utilization including ICU. 
Our limited experience supports the results from the current literature and suggests that ACs in selected patients is safe, practical and economic surgical method and decrease the frequency of functional deficits despite the extensive resection. We found that operative time is comparable to and blood loss is much less than that of craniotomy under general anesthesia. We did not encounter intraoperative seizure in this series and it has been demonstrated that seizure during stimulation is easily controlled with cold water (10). However, anesthesiology team must be ready for the possibility of intraoperative seizure which if appropriate intervention is not done on time, AC may fail and general anesthesia must be undertaken. Most patients were transferred to the ward and ICU stay was very short in our patient group, which is in line with the current literature (6). We found that $A C$ with subcortical white matter mapping very useful in identifying subcortical motor fibers which might have displaced by tumors and saving of them may avoid irreversible motor deficits. Surgeon should be careful when resection of the functional area especially language cortex, showing negative mapping. It has been clearly demonstrated that cortical sites essential for language may be different from the well-known gross anatomy of Broca-Wernicke (9). Furthermore, functional sites may have displaced by the tumor so the traditional anatomy should not be the target that should be saved. We suggest that the cortex showing negative mapping should be stimulated at least three times to be sure that area is not eloquent. Despite all the measures that we take, the literature demonstrated that almost $5 \%$ of patients showed permanent neurological deficit after resection of the area with negative mapping (15). This suggest that negative brain mapping does not guarantee the absence of functional cortex and despite cortical mapping, resection of such eloquent cortex or close associated areas is still challenging and continues to be a potential risk for patients. For decreasing the rate of permanent neurological deficits, our experience supported the electrical stimulation not only for the cortex but also white matter underneath.

The importance of the role of anesthesiology during $A C$ is clearly understood in case of any complication occurred during resection or stimulation. Obstructive apnea, nausea, vomiting, seizure and loss of consciousness are the most frequent complications that have been reported (2). Obstructive apnea and hypoventilation are the two especially important complications that can cause hypoxia and hypercarbia. Expired $\mathrm{CO}_{2}$ should be monitored meticulously and head positioning should be revised over and over. Nausea and vomiting may be reduced by administration of metoclopramide and hypertensive and tachycardia may be decreased by administering vasodilators and $\beta$-blockers. One of the most frightening complications during $\mathrm{AC}$ is seizure that could cause failure of surgery or stimulation, brain herniation, hypoxia, and head or neck injury as the head is stabilized by the three-pinned head holder. Fortunately, intraoperative seizure is generally controlled by irrigation with cold water and if cold water fails, intravenous administration of anti-epileptic medication should be considered promptly. Another measure that anesthesiologist should take into consideration is pain control during the dura opening. Analgesia and sedation help the patient to overcome restlessness and agitation. In the present series, which includes limited number of the patients, we did not encounter any complication during surgery which in the literature ranges from $16 \%$ to $20 \%$ (2). Furthermore there was no major or minor complication related to surgery itself such as wound complications, postoperative hematomas, and uncontrollable seizure. We have to underline that the low rate of peroperative complication in the present series may largely be due to the smaller number of patients who underwent AC. An experienced team including surgeons and anesthesiologists is the cornerstone of the successful awake surgery and decreasing the complication rate in peroperative period.

\section{CONCLUSION}

Depending on our own experience and larger retrospective and limited prospective studies, awake craniotomy with intraoperative electrical cortical stimulation is effective, safe and practical approach for lesions related to the functional cortex itself or close to it. It is well tolerated by the patients and irreversible neurological deficits are less common. It avoids complications of general anesthesia and is associated with low complication and mortality rates of surgery and hospital stay is short including the intensive care unit, which decreases the economic burden.

\section{ACKNOWLEDGEMENTS}

The authors thank to Medical Students Baris Chousein and Burak Capar who spent time for retrieving the patients' files to the present study.

\section{REFERENCES}

1. Berger MS, Deliganis AV, Dobbins J, Keles GE: The effect of extent of resection on recurrence in patients with low grade cerebral hemisphere gliomas. Cancer 74: 1784-1791, 1994

2. Bonhomme V, Franssen C, Hans P: Awake craniotomy. Eur J Anesthesiol 26: 906-912, 2009

3. Cushing $\mathrm{H}$ : A note upon the faradic stimulation of the postcentral gyrus in conscious patients. Brain 32: 44-53, 1909

4. De Sloovere D, De Deyne C, Wuyts J, Heylen R: Bispectral index monitoring during asleep-awake technique for craniotomy. Eur J Anaesthesiol 26: 443-444, 2009

5. Foerster $\mathrm{O}$, Penfield $\mathrm{W}$ : The structural basis of traumatic epilepsy and results of radical operation. Brain 53: 99-119, 1930

6. Frost EA, Booij LH: Anesthesia in the patient for awake craniotomy. Curr Opin Anaesthesiol 20: 331-335, 2007

7. Gupta DK, Chandra PS, Ojha BK, Sharma BS, Mahapatra AK, Mehta VS: Awake craniotomy versus surgery under general anesthesia for resection of intrinsic lesions of eloquent cortex-A prospective randomised study. Clin Neurol Neurosurg 109: 335-342, 2007 
8. Huncke K, Van de Wiele B, Fried I, Rubinstein EH: The asleepawake-asleep anesthetic technique for intraoperative language mapping. Neurosurgery 42: 1313-1316, 1998

9. Ojemann G, Ojemann J, Lettich $E$, Berger $M$ : Cortical language localization in left, dominant hemisphere. An electrical stimulation mapping investigation in 117 patients. J Neurosurg 71: 316-326, 1989

10. Olivier A, Boling W, Tanriverdi T: Techniques in Epilepsy Surgery: The MNI Approach. Cambridge: Cambridge University Press, 2012

11. Penfield W, Pasquet A: Combined regional and general anesthesia for craniotomy and cortical exploration. Part 1. Neurosurgical considerations. Int Anesthiol Clin 24:1-20, 1986

12. Penfield W: Some mechanisms of consciousness discovered during electrical stimulation of the brain. Proc N.A.S 44: 5166,1958
13. Pereira LCM, Oliveira KM, L'Abbate GL, Sugai R, Ferreira JA, da Motta LA: Outcome of fully awake craniotomy for lesions near the eloquent cortex: Analysis of a prospective surgical series of 79 supratentorial primary brain tumors with long followup. Acta Neurochir 151: 1215-1230, 2009

14. Sacko O, Lauwers-Cancers V, Sesay M, Brenner A, Roux FE: Awake craniotomy vs surgery under general anesthesia for resection of supratentorial lesions. Neurosurgery 68: 11921199, 2011

15. Serletis D, Bernstein M: Prospective study of awake craniotomy used routinely and nonselectively for supratentorial tumors. J Neurosurg 107: 1-6, 2007

16. Taylor MD, Bersntein M: Awake craniotomy with brain mapping as the routine surgical approach to treating patients with supratentorial intraaxial tumors: A prospective trial of 200 cases. J Neurosurg 90: 35-41, 1999 